\title{
Penyisihan Surfaktan dari Limbah Laundry dengan Media Artifisial Kapur-Semen
}

\author{
Silvana Herrari ${ }^{1}$, Agus Slamet ${ }^{2}$, Ipung Fitri Purwanti ${ }^{3}$ \\ Departemen Teknik Lingkungan, Institut Teknologi Sepuluh Nopember \\ Surel: ${ }^{2}$ silvanaherrari@gmail.com, ${ }^{2}$ agus.tlits@gmail.com
}

\begin{abstract}
ABSTRAK
Air limbah laundry yang tidak diolah dapat berdampak buruk pada keseimbangan ekosistem badan air. Air limbah laundry yang banyak mengandung surfaktan akan mengakibatkan pembusaan pada badan air. Kapur telah dikenal dapat menyisihkan surfaktan melalui proses koagulasi-flokulasi. Penggaraman surfaktan dengan media artifisial kapur-semen sebagai media roughing filter perlu dikembangkan. Tujuan penelitian ini adalah untuk menentukan diameter media artifisial kapursemen dan beban hidrolik optimum. Sampel air limbah laundry diambil dari salah satu usaha laundry di Kelurahan Kebonsari Surabaya. Penelitian diawali dengan menganalisis karakteristik sampel air limbah laundry. Penelitian dilakukan secara kontinyu dengan variasi diameter media artifisial kapur-semen (5 mm dan $10 \mathrm{~mm}$ ) dan debit (Q1 dan Q2). Variasi debit digunakan untuk menentukan nilai beban hidrolik optimum. Garam yang terbentuk diendapkan menggunakan sand filter. Parameter yang digunakan dalam penelitian kontinyu adalah surfaktan dan $\mathrm{pH}$. Selanjutnya dilakukan analisis perubahan konsentrasi parameter dan pengaruh diameter media-beban hidraulik terhadap efisiensi penyisihan surfaktan menggunakan perangkat lunak Minitab 16.1.0.0. Karakteristik awal sampel air limbah laundry mengandung surfaktan sebesar 18,32 $\mathrm{mg} / \mathrm{L}$ dan $\mathrm{pH} 8,3$. Media artifisial kapur-semen dengan diameter $5 \mathrm{~mm}$ dan debit $240 \mathrm{~mL} /$ menit atau beban hidrolik $0,029 \mathrm{~m}^{3} / \mathrm{m}^{2}$.menit menunjukkan penyisihan surfaktan pada air limbah laundry yang paling baik yaitu sebesar $69,81 \%$. Faktor diameter dan debit memiliki efek yang signifikan dalam menyisihkan surfaktan. Interaksi antar faktor diameter dan debit tidak memiliki efek yang signifikan dalam menyisihkan surfaktan.
\end{abstract}

\section{Kata kunci}

Kapur, Laundry, Media, Penggaraman, Surfaktan

\section{PENDAHULUAN}

Kegiatan laundry menghasilkan air limbah yang mengandung konsentrasi senyawa kimia yang tinggi dari penggunaan sabun dan deterjen, suspended solid, dan minyak $^{[1]}$. Kegiatan laundry rata-rata menggunakan $15 \mathrm{~L}$ air untuk $1 \mathrm{~kg}$ proses pencucian dan membuang air limbah sebanyak $400 \mathrm{~m}^{3}$ per hari ${ }^{[2]}$. Komponen utama dari deterjen adalah surfaktan yang memiliki kemampuan menyisihkan partikulat dan padatan berminyak. Linear Alkyl Benzene Sulfonate (LAS) adalah anion surfaktan utama yang digunakan pada deterjen ${ }^{[3]}$. Deterjen 
juga mengandung fosfat untuk meningkatkan daya pembersih yang lebih besar dengan menyisihkan ion kalsium dan magnesium yang berada dalam air ${ }^{[4]}$. Surfaktan yang banyak digunakan di Indonesia adalah jenis LAS yang penyusun utamanya adalah senyawa sodium dodecybenzene sulfonate (NaDBS) dan sodium tripolyphosphate $(\mathrm{STPP})^{[5]}$.

Kandungan pencemar yang tinggi pada air limbah laundry dapat berdampak terhadap kehidupan biota air. Efek beracun air limbah laundry ${ }^{[1]}$ dibagi berdasarkan sumber pencemar yaitu deterjen, surfaktan, dan oil/grease. Deterjen dapat menghancurkan selaput lendir ikan dan beracun terhadap ikan pada konsentrasi mendekati 15 ppm. Surfaktan dapat menimbulkan busa pada air permukaan yang dapat mengurangi transfer oksigen pada air ${ }^{[6]}$. Oil/grease mempengaruhi tranparansi dan kandungan Dissolved Oxygen (DO) air. Fosfat yang terkandung dalam deterjen dapat mengakibatkan eutrofikasi di badan air. Eutrofikasi terjadi akibat kelebihan nutrisi pada lingkungan sehingga meningkatkan pertumbuhan alga yang dapat mengganggu keseimbangan daya dukung terhadap biota air ${ }^{[4]}$.

Air limbah laundry yang banyak mengandung surfaktan dapat diolah melalui proses koagulasi-flokulasi ${ }^{[3]}$, adsorpsi ${ }^{[7]}$, dan biologis ${ }^{[7]}$. Proses adsorpsi efektif dilakukan jika konsentrasi polutan yang akan diolah rendah $^{[7],[8]}$. Proses biologis memiliki biaya operasional yang lebih rendah dibanding dengan proses kimia, tetapi membutuhkan waktu reaksi yang lama dan resiko kematian biomassa $^{[7]}$. Metode penurunan surfaktan dapat menggunakan proses penggaraman dengan ion-ion $\mathrm{Ca}^{2+}$. Kapur banyak digunakan sebagai koagulan efektif untuk menyisihkan surfaktan dengan proses penggaraman ${ }^{[5]}$. Senyawa NaDBS dan STTP dapat membentuk endapan bila bereaksi dengan logam alkali tanah dan logam transisi. Reaksi antara NaDBS dan STTP dengan logam alkali tanah adalah ${ }^{[5]}$ :

$$
\begin{aligned}
& 2 \mathrm{C}_{12} \mathrm{H}_{25} \mathrm{C}_{6} \mathrm{H}_{5} \mathrm{SO}_{3} \mathrm{Na}+\mathrm{Ca}(\mathrm{OH})_{2} \\
& \mathrm{Ca}\left(\mathrm{C}_{12} \mathrm{H}_{25} \mathrm{C}_{6} \mathrm{H}_{5} \mathrm{SO}_{3}\right)_{2}+2 \mathrm{NaOH}
\end{aligned}
$$

$2 \mathrm{Na}_{5} \mathrm{P}_{3} \mathrm{O}_{10}+5 \mathrm{Ca}(\mathrm{OH})_{2} \rightarrow \mathrm{Ca}_{5}\left(\mathrm{P}_{3} \mathrm{O}_{10}\right)_{2}+$ $10 \mathrm{NaOH}$

Kelemahan dari proses tersebut adalah terbentuknya volume lumpur yang banyak, sehingga dibutuhkan penelitian teknologi pengolahan air limbah laundry yang dapat berjalan lebih efisien.

Proses penggaraman surfaktan dengan menggunakan filter media berbutir yang mengandung $\mathrm{Ca}$ perlu dikembangkan. Media artifisial berbutir dari campuran kapur-semen mampu melepaskan ion $\mathrm{Ca}^{2+}$ yang akan bereaksi dengan surfaktan. Kelebihan dari penggunaan media artifisial kapur-semen ini adalah penggunaannya yang mudah bagi pelaku usaha laundry. Penggunaan filter tidak memerlukan peralatan mekanik yang canggih $^{[9]}$. Konsep filter yang digunakan pada penelitian ini adalah roughing filter (RF). Biasanya RF digunakan untuk menurunkan kekeruhan dan padatan tersuspensi di dalam air. Air dilewatkan pada bak dengan media kasar seperti kerikil, limestone, atau gerabah. RF memiliki kapasitas tempat pengendapan parikulat yang besar dan headloss yang rendah karena porinya yang besar ${ }^{[9]}$. RF dengan media artifisial kapur-semen dapat menjadi media koagulasi-flokulasi sekaligus pengendapan ${ }^{[8],[10]}$. Penelitian dilakukan untuk mengetahui kemampuan media artifisial kapur-semen dalam menyisihkan surfaktan.

\section{METODE PENELITIAN}

Variasi diameter media artifisial kapursemen yang diggunakan adalah 5 dan $10 \mathrm{~mm}$. Variasi diameter media artifisial berdasarkan $^{[11]}$ yang menggunakan media filter berukuran 2,5-10 mm untuk mencegah clogging. Variasi debit yang digunakan adalah Q1 dan Q2. Variasi debit digunakan untuk menentukan nilai beban hidrolik optimum. Pada pembahasan selanjutnya akan menggunakan penjelasan variasi debit untuk memudahkan interpretasi. Variasi debit yang masuk pada reaktor berdasarkan kriteria desain kecepatan filtrasi RF $(0,3-1,5$ $\mathrm{m} / \mathrm{jam})^{[12]}$.

Berikut adalah perhitungan debit yang masuk ke filter,

$\begin{array}{ll}\text { Lebar reaktor } & =12 \mathrm{~cm} \\ \text { Tinggi reaktor } & =7 \mathrm{~cm}\end{array}$ 
Panjang reaktor

Luas penampang filter (A)
$=1 \mathrm{~m}=100 \mathrm{~cm}$

$=12 \mathrm{~cm} \mathrm{x} 7 \mathrm{~cm}$

$=84 \mathrm{~cm}^{2}$

$=0,0084 \mathrm{~m}^{2}$

- Direncanakan debit yang masuk (Q1) 120 $\mathrm{ml} /$ menit atau $0,00012 \frac{\mathrm{m}^{3}}{\mathrm{menit}}$, dicek kecepatan (v) filtrasi adalah:

$$
\begin{aligned}
\mathrm{v}=\frac{\mathrm{Q}}{\mathrm{A}}=\frac{0,00012 \frac{\mathrm{m}^{3}}{\mathrm{menit}}}{0,0084 \mathrm{~m}^{2}} \\
=0,0143 \mathrm{~m} / \mathrm{menit} \\
=0,86 \mathrm{~m} / \mathrm{jam}
\end{aligned}
$$

Perkiraan waktu tinggalnya (Td) adalah:

$$
\begin{aligned}
\mathrm{Td}=\frac{\text { Vol }}{\mathrm{Q}}=\frac{\mathrm{A} \times \text { Panjang reaktor }}{\mathrm{Q}} & \begin{array}{r}
0,0084 \mathrm{~m}^{2} \times 1 \mathrm{~m} \\
0,00012 \frac{\mathrm{m}^{3}}{\mathrm{menit}}
\end{array} \\
& =70 \text { menit }
\end{aligned}
$$

Beban hidrolik pada debit ini adalah:

$$
\begin{aligned}
\text { Beban hidrolik } & =\frac{\mathrm{Q}}{\text { Luas penampang }(\mathrm{A})} \\
& =\frac{0,00012 \frac{\mathrm{m}^{3}}{\mathrm{menit}}}{0,0084 \mathrm{~m}^{2}} \\
& =0,0143 \mathrm{~m}^{3} / \mathrm{m}^{2} . \text { menit }
\end{aligned}
$$

- Direncanakan debit yang masuk (Q2) 240 $\mathrm{ml} / \mathrm{menit}$ atau $0,00024 \frac{\mathrm{m}^{3}}{\text { menit }^{\prime}}$, dicek kecepatan (v) filtrasi adalah:

$$
\begin{aligned}
& \mathrm{v}=\frac{\mathrm{Q}}{\mathrm{A}}=\frac{0,00024 \frac{\mathrm{m}^{3}}{\mathrm{menit}}}{0,0084 \mathrm{~m}^{2}}=0,0286 \frac{\mathrm{m}}{\text { menit }} \\
& =1,71 \mathrm{~m} / \mathrm{jam}
\end{aligned}
$$

Perkiraan waktu tinggalnya (Td) adalah:

$\mathrm{Td}=\frac{\mathrm{Vol}}{\mathrm{Q}}=\frac{\mathrm{A} \times \text { Panjang reaktor }}{\mathrm{Q}}=$ $\frac{0,0084 \mathrm{~m}^{2} \times 1 \mathrm{~m}}{0,00024 \frac{\mathrm{m}^{3}}{\mathrm{menit}}}=35$ menit

Beban hidrolik pada debit ini adalah:

$$
\begin{aligned}
\text { Beban hidrolik } & =\frac{\mathrm{Q}}{\text { Luas penampang }(\mathrm{A})} \\
& =\frac{0,00024 \frac{\mathrm{m}^{3}}{\mathrm{menit}}}{0,0084 \mathrm{~m}^{2}} \\
& =0,0286 \mathrm{~m}^{3} / \mathrm{m}^{2} . \text { menit }
\end{aligned}
$$

\section{Alat dan Bahan}

Sampel air limbah laundry yang digunakan dalam penelitian ini adalah dari salah satu usaha laundry di Kelurahan Kebonsari, Surabaya. Sampel air limbah yang diambil adalah air limbah dari proses pemberian deterjen hingga pembilasan terakhir. Volume air limbah dari 1 mesin cuci adalah sekitar 30 L. Pengambilan sampel air limbah dilakukan menggunakan jerigen $20 \mathrm{~L}$ sebanyak 2 buah untuk $1 \mathrm{x}$ pengambilan air limbah. Pada sistem kontinyu dibutuhkan 67,2 $\mathrm{L}$ sehingga dibutuhkan $3 \mathrm{x}$ pengambilan air limbah dari 1 mesin cuci. Metode pengambilan sampel air limbah yang digunakan adalah sampel sesaat (grab sample). Sampel yang digunakan adalah dari 1 mesin cuci yang sama dalam satu lokasi kegiatan laundry pada waktu yang berbeda, dengan volume yang sama.

Bahan yang digunakan untuk membuat media artifisial kapur-semen adalah bubuk kapur tohor $(\mathrm{CaO})$ dan semen portland. Bubuk kapur tohor $(\mathrm{CaO})$ yang digunakan berasal dari pertambangan kapur di Tuban, Jawa Timur. Adonan kapur dan semen akan dibuat dengan total berat campuran per 1000 gr. Komposisi media artifisial kapur-semen yang digunakan berdasarkan percobaan secara batch yang telah dilakukan terlebih dahulu yaitu 7:1. Kebutuhan kapur dan semen rasio $7: 1$ berdasarkan rasio by weight dengan total berat campuran sebesar 1000 gr adalah 875 gr kapur dan 125 gr semen.

Rasio by weight digunakan agar komposisi air pada masing-masing rasio kapur-semen sama, yaitu sekitar 20\% hingga $30 \%{ }^{[13]}$. Hal tersebut agar adonan tidak terlalu cair sehingga memudahkan saat mencetak. Adonan berbentuk pasta dicetak pada sedotan berdiameter $5 \mathrm{~mm}$ (Gambar 1). Adonan dimasukkan ke dalam sedotan menggunakan plastik segitiga atau papping bag (Gambar 2c). Kemudian dibiarkan selama kurang lebih 2 jam agar setengah kering, lalu dikeluarkan dari cetakan dan dipotong tiap $10 \mathrm{~mm}$. Media yang sudah dipotong lalu dikeringkan selama kurang lebih 2 hari pada suhu ruangan kemudian dioven minimal selama 1 jam untuk mengurangi kadar air. 


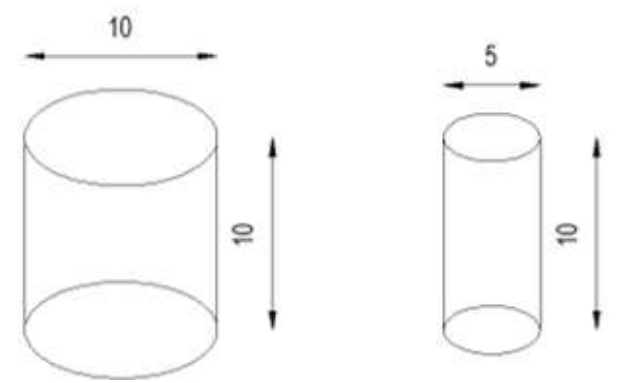

Gambar 1. Ukuran media artifisial kapursemen

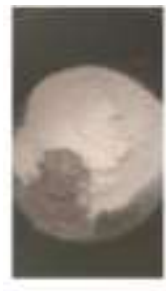

(a)



(b)

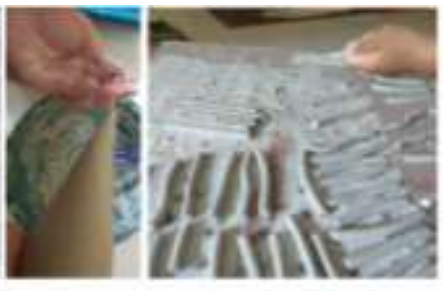

(c) (d)
Gambar 2. Proses pembuatan media artifisial kapur-semen; (a) bubuk kapur-semen; (b) adonan pasta; (c) penggunaan papping bag; (d) pengeluaran dari cetakan dan pengeringan

\section{Prosedur Penelitian}

Pada penelitian ini menggunakan reaktor horizontal flow roughing filter (HRF) yang terbuat dari talang air PVC dengan ukuran 110x12x12 cm. Reaktor HRF yang berisi media artifisial kapur-semen berukuran yaitu 100x12x7 cm. Volume reaktor HRF yang berisi media artifisial kapur-semen adalah 8,4 L. Running dilakukan 2x per 1 variasi, sehingga air limbah yang dibutuhkan adalah $\quad 8,4 \mathrm{~L} \times 4$ reaktor $\times 2 \times$ running $=$ 67,2 L. Sampel air limbah laundry ditampung dalam holding tank berukuran 150 L. Sampel air limbah yang ditampung di holding tank dipompa menggunakan submersible pump menuju bak penampung. Volume bak penampung adalah 50 L. Pompa yang digunakan memiliki head 3 meter.

Media artifisial kapur-semen dimasukkan ke dalam reaktor hingga terendam air limbah. Sampel air limbah yang melewati media artifisial kapur-semen dialirkan secara horizontal flow. Setelah melewati media artifisial kapur-semen, terbentuk presipitat yang diendapkan dengan sand filter. Reaktor sand filter menggunakan toples plastik berdiameter 11,6 $\mathrm{cm}$ berisi pasir sungai. Pasir diayak menggunakan saringan mesh 35 atau diameter $0,5 \mathrm{~mm}$ yang kemudian dicuci dengan air bersih dan disaring dengan saringan mesh 50 atau diameter $0,3 \mathrm{~mm}$, sehingga pasir yang digunakan memiliki diameter $0,3-0,5 \mathrm{~mm}$. Penahan pasir pada sand filter menggunakan kapas busa aquarium sebanyak 3 lapis. Total kedalaman sand filter adalah $10 \mathrm{~cm}$ dengan rincian kedalaman pasir $6 \mathrm{~cm}$ dan kapas busa $4 \mathrm{~cm}$. Tahapan proses penelitian secara kontinyu dapat dilihat pada Gambar 3

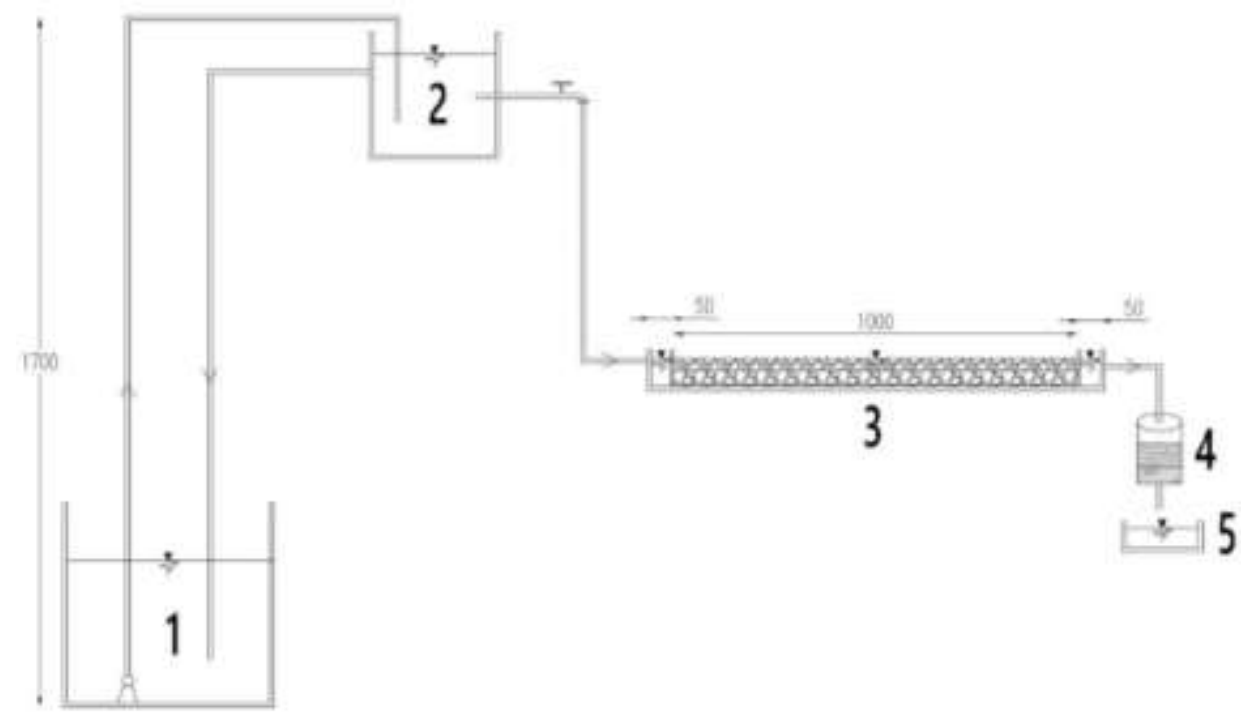

Gambar 3. Tahapan proses penelitian secara kontinyu

\footnotetext{
$\begin{array}{cl}\text { Keterangan: } & \\ \text { 1. } & \text { Bak penampung berukuran } 150 \mathrm{~L} \\ 2 . & \text { Holding tank berukuran } 50 \mathrm{~L}\end{array}$

HRF berisi media artifisial kapur-semen

Bak sand filter

Bak effluent
} 
Proses penggaraman pada sistem kontinyu menggunakan konsep RF dengan aliran horizontal. Komposisi media artifisial kapur-semen yang optimum dari sistem batch digunakkan pada sistem kontinyu. Pada sistem kontinyu menggunakan variasi diameter media artifisial kapur-semen (10 dan $5 \mathrm{~mm}$ ) dan beban hidrolik (120 dan 240 $\mathrm{ml} / \mathrm{menit}$ ). Sebanyak 4 reaktor HRF beroperasi secara kontinyu. yang terbagi sesuai variasi diameter media artifisial kapursemen dan beban hidrolik (Tabel 1). Presipitat yang terbentuk dipisahkan dengan sand filter. Kemudian efluen diuji kandungan surfaktan dan $\mathrm{pH}$ sesuai dengan Standard Methods for the Examination of water and Wastewater (SMWW) (Tabel 2). Pengujian dilakukan secara duplo.

Tabel 1. Matriks variabel penelitian secara kontinyu

\begin{tabular}{ccc}
\hline \multirow{2}{*}{ Beban hidrolik } & \multicolumn{2}{c}{ Diameter Media Kapur:Semen } \\
\cline { 2 - 3 } & $5 \mathrm{~mm}$ & $10 \mathrm{~mm}$ \\
\hline Q1 & $5-1$ & $10-1$ \\
Q2 & $5-2$ & $10-2$ \\
\hline
\end{tabular}

Tabel 2. Metode analisis parameter

\begin{tabular}{lll}
\hline No. & Parameter & Metode Analisis \\
\hline 1. & Surfaktan & MBAS (SMWW 5540) \\
2. & pH & SNI 06-6989 11-2004 \\
\hline
\end{tabular}

\section{HASIL DAN PEMBAHASAN}

Penelitian ini dilakukan dalam skala laboratorium untuk mengetahui efisiensi penyisihan surfaktan. Proses penyisihan surfaktan pada limbah laundry dilakukan dengan cara mengalirkan air limbah melalui media artifisial kapur-semen. Media artifisial kapur-semen yang dilewati air limbah laundry akan melepaskan ion logam $\mathrm{Ca}^{2+}$. Ion logam $\mathrm{Ca}^{2+}$ akan bereaksi dengan surfaktan membentuk endapan garam. Endapan garam tersebut dipisahkan dengan sand filter.

\section{Karakteristik Air Limbah Laundry}

Karakteristik sampel air limbah laundry adalah keruh, berwarna keabu-abuan, dan berbau wangi karena efek pemberian deterjen dan pewangi pakaian (Gambar 4). Mesin cuciyang digunakan usaha laundry tersebut adalah mesin cuci otomatis front loading.
Pemberian deterjen dan pewangi pakaian pada mesin cuci dilakukan sebelum pencucian dimulai. Tahapan proses pencucian adalah pembasahan, penyabunan, pembilasan, dan pemerasan. Proses pencucian berlangsung selama 30 menit. Berdasarkan hasil analisis karakteristik air limbah laundry dapat pada Tabel 3. Konsentrasi surfaktan sampel air limbah laundry melebihi baku mutu, sehingga dibutuhkan pengolahan sebelum air limbah tersebut dibuang ke badan air.

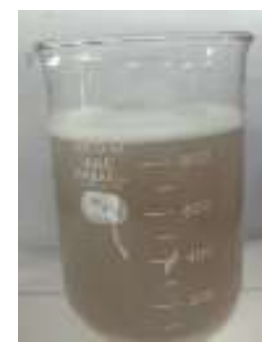

Gambar 4. Sampel air limbah laundry

Tabel 3. Karakteristik air limbah laundry

\begin{tabular}{lccc} 
Parameter & Satuan & $\begin{array}{l}\text { Konsentrasi } \\
\text { sampel }\end{array}$ & $\begin{array}{l}\text { Kadar } \\
\text { maksimum* }\end{array}$ \\
\hline $\begin{array}{l}\text { MBAS } \\
\text { (deterjen) } \\
\text { pH }\end{array}$ & $\mathrm{mg} / \mathrm{L}$ & 18,32 & 10 \\
\hline
\end{tabular}

*) Berdasarkan Peraturan Gubernur Jawa Timur No 72 Tahun 2013

\section{Pengaruh Diameter Media Artifisial Kapur -Semen Dan Debit Terhadap Surfaktan}

Konsentrasi surfaktan awal sampel air limbah laundry adalah 18,32 mg/L. Media artifisial kapur-semen berdiameter $5 \mathrm{~mm}$ mampu menyisihkan surfaktan lebih besar dibanding dengan media berdiameter $10 \mathrm{~mm}$ (Gambar 5). Hal tersebut dikarenakan luas permukaan media artifisial kapur-semen berdiameter $5 \mathrm{~mm}$ lebih besar sehingga air limbah dapat kontak dengan media semakin baik $^{[11] .}$ Rata-rata penyisihan surfaktan dengan media artifisial kapur-semen berdiameter 5 $\mathrm{mm}$ pada debit $120 \mathrm{ml} / \mathrm{menit}$ dan 240 $\mathrm{ml} /$ menit masing-masing sebesar $54,45 \%$ dan $69,81 \%$. Rata-rata penyisihan surfaktan dengan media artifisial kapur-semen berdiameter $10 \mathrm{~mm}$ pada debit $120 \mathrm{ml} / \mathrm{menit}$ dan $240 \mathrm{ml} / \mathrm{menit}$ masing-masing sebesar $37,28 \%$ dan $57,83 \%$. Penyisihan surfaktan pada debit $240 \mathrm{ml} / \mathrm{menit}$ lebih besar dibanding dengan debit $120 \mathrm{ml} / \mathrm{menit}$. Hal 
tersebut dikarenakan ion $\mathrm{Ca}^{2+}$ lebih banyak lepas pada debit $240 \mathrm{ml} / \mathrm{menit}$ akibat kecepatan aliran yang lebih besar. Penyisihan surfaktan terjadi akibat kontak dengan ion $\mathrm{Ca}^{2+}$ yang lepas dari media artifisial kapur- semen kemudian membentuk presipitat, mengacu pada (1) dan (2) ${ }^{[5]}$. Hasil analisis penyisihan surfaktan dari pengambilan sampling secara duplo dapat dilihat pada Gambar 6.

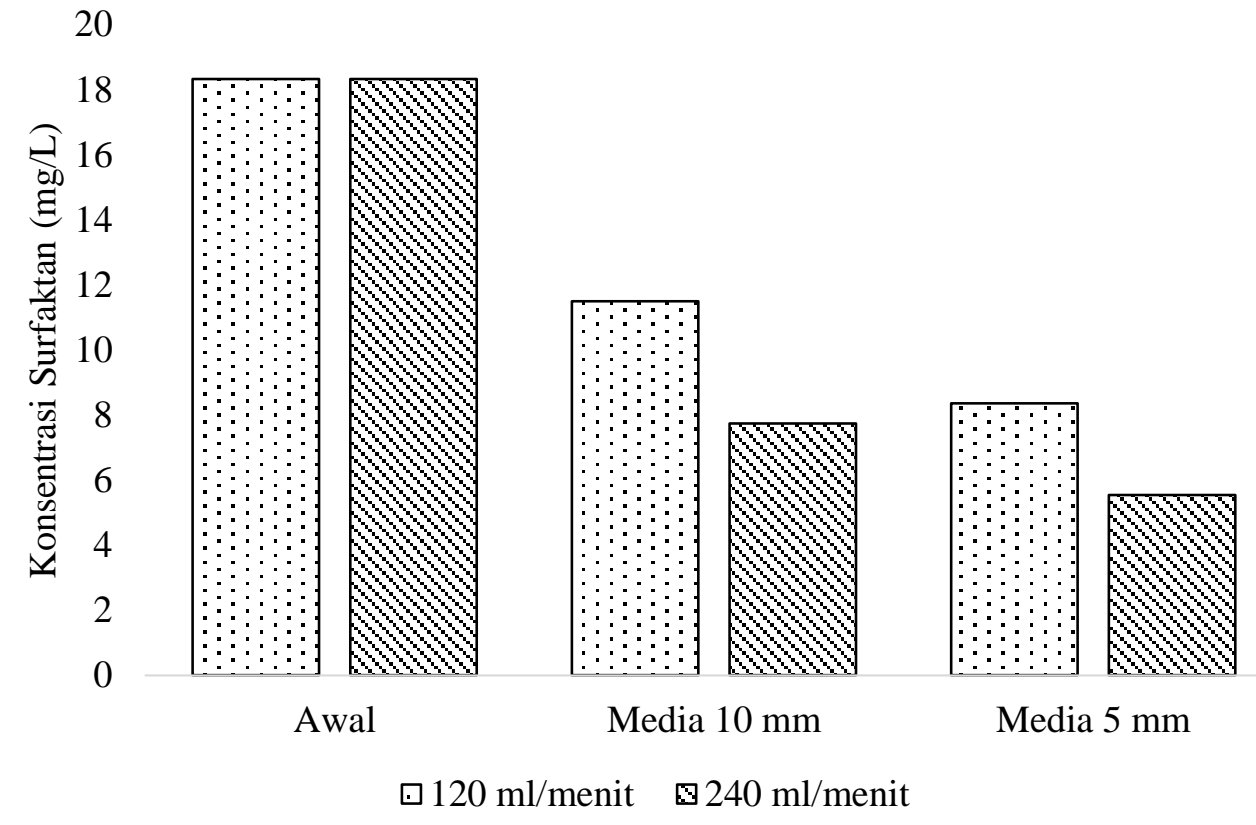

Gambar 5. Rata-rata penyisihan surfaktan pada percobaan kontinyu

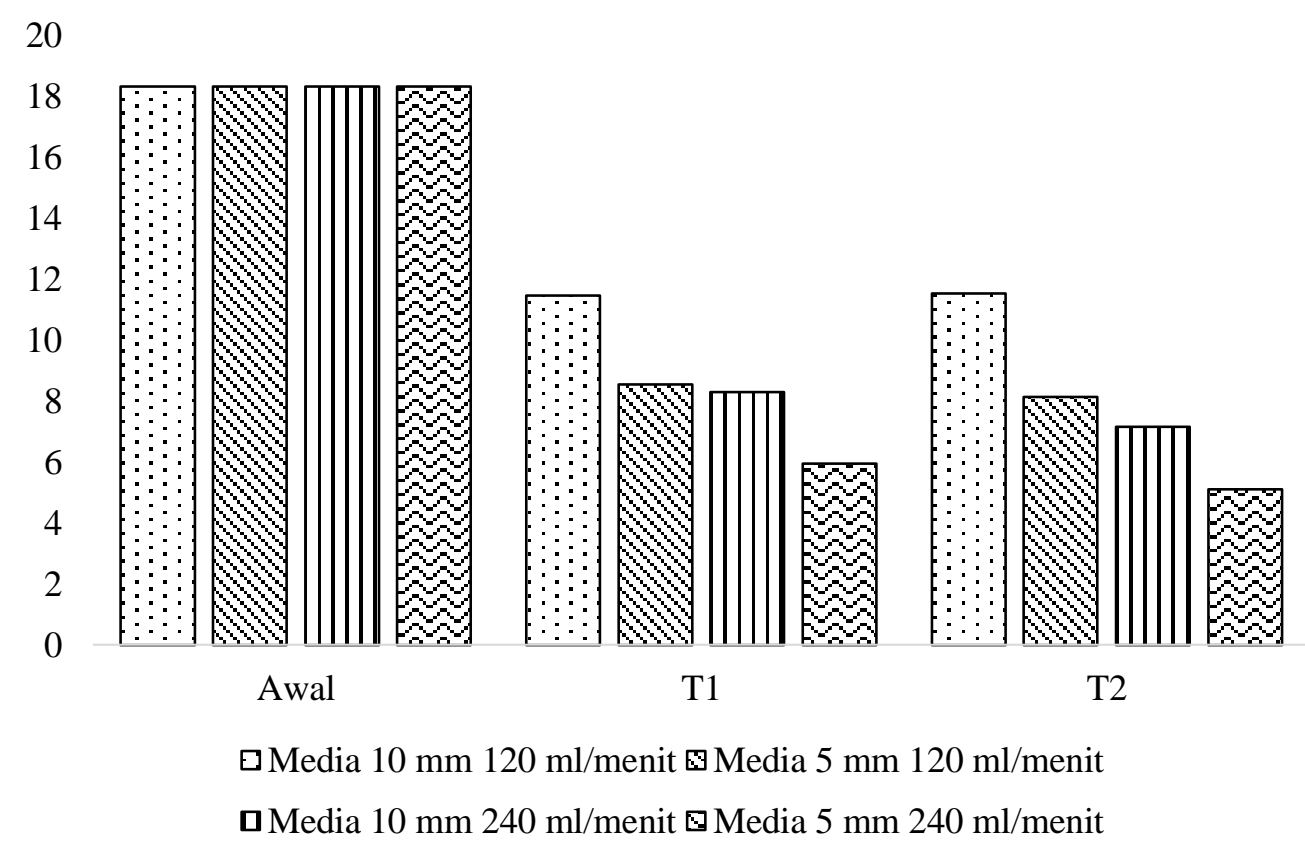

Gambar 6. Penyisihan surfaktan pada percobaan kontinyu (duplo)

Pengaruh diameter media artifisial kapursemen dan debit terhadap $\mathrm{pH}$

pH awal sampel air limbah laundry adalah 8,3. Rata-rata kenaikan $\mathrm{pH}$ dengan media artifisial kapur-semen berdiameter 10 $\mathrm{mm}$ pada debit $120 \mathrm{ml} / \mathrm{menit}$ dan 240 $\mathrm{ml} /$ menit masing-masing sebesar $45 \%$ dan $42 \%$ (Gambar 7). Rata-rata kenaikan $\mathrm{pH}$ dengan media artifisial kapur-semen berdiameter $5 \mathrm{~mm}$ pada debit $120 \mathrm{ml} / \mathrm{menit}$ 
dan $240 \mathrm{ml} /$ menit masing-masing sebesar $39 \%$ dan $44 \%$ (Gambar 7). Kenaikan $\mathrm{pH}$ yang cukup signifikan menandakan bahwa $\mathrm{CaO}$ terlepas dari media artifisial kapur-semen dan bereaksi dengan air membentuk ion $\mathrm{OH}^{-}{ }^{-5]}$. $\mathrm{pH}$ yang tinggi dapat mengganggu keseimbangan kehidupan biota akuatik, sehingga diperlukan proses netralisasi $\mathrm{pH}$ sebelum air limbah dibuang ke badan air. Hasil analisis kenaikan $\mathrm{pH}$ dari pengambilan sampling secara duplo dapat dilihat pada Gambar 8.

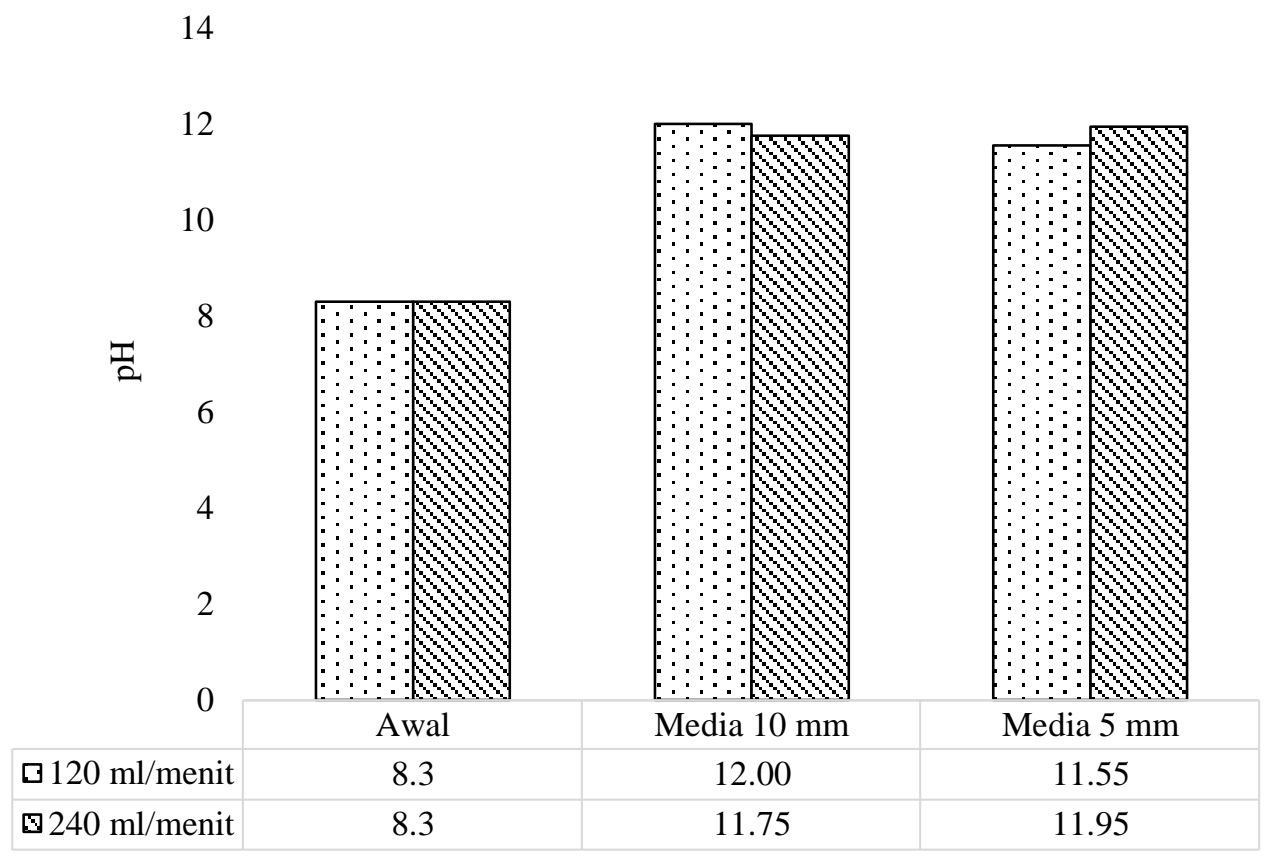

Gambar 7. Rata-rata kenaikan pH pada percobaan kontinyu

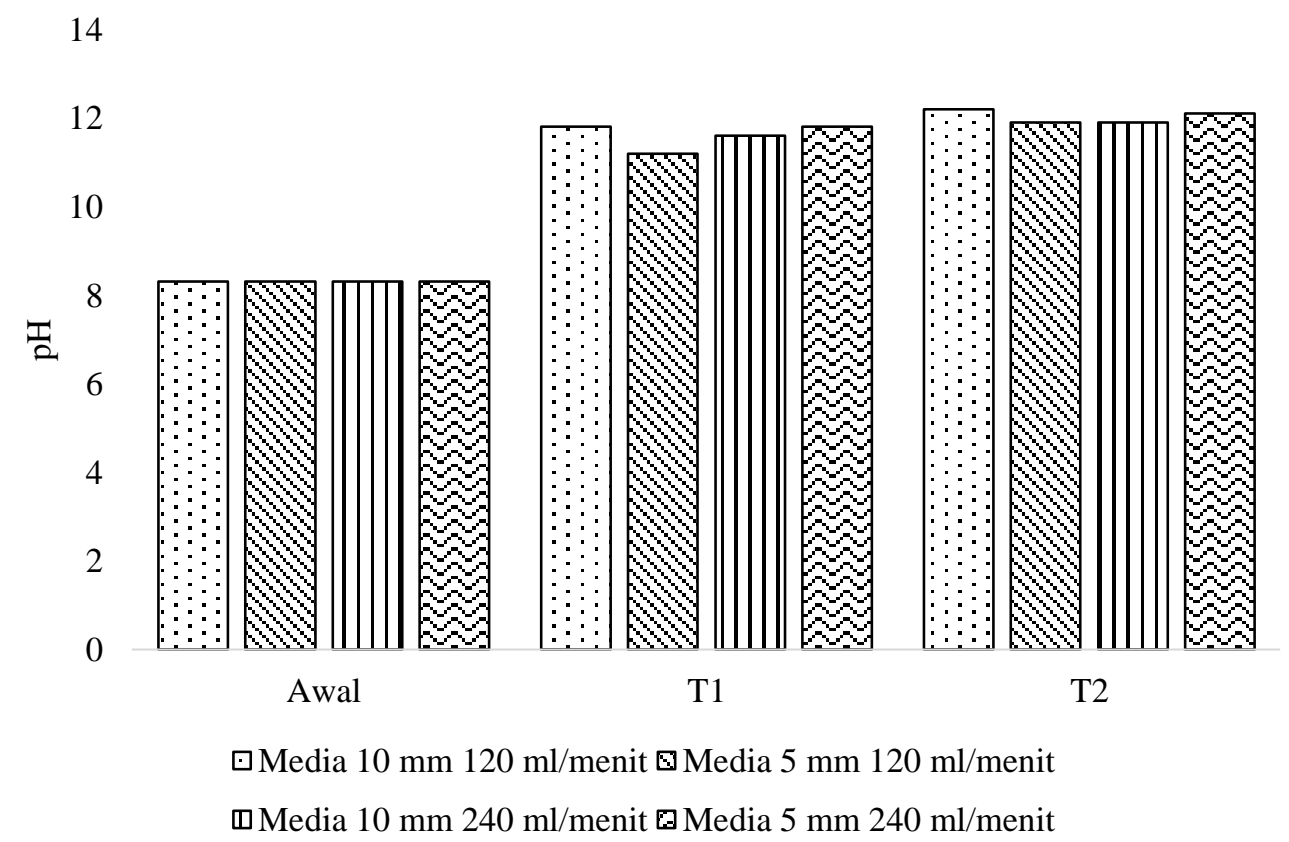

Gambar 8. Kenaikan pH pada percobaan kontinyu (duplo) 


\section{Analisis Statistik Menggunakan Design Of Experiment (DOE) Minitab 16.1.0.0.}

Design of experiment (DOE) adalah sebuah tes dengan membuat perubahan pada variabel input agar dapat diidentifikasi perubahan yang terjadi pada output dari proses tersebut. Analisis data menggunakan DOE berfokus pada metode factorial design. Metode factorial design dapat menganalisis efek secara simultan dari faktor diameter media artifisial kapur-semen dan debit pada penelitian ini. Metode factorial design mampu memvisualisasikan faktor utama dan interaksi faktor pada penelitian melalui factorial plot. Metode factorial design juga dapat menentukan pengaturan faktor untuk mengoptimalkan hasil melalui response optimizer.

Hasil analisis dengan factorial design yaitu faktor diameter dan debit pada respon $\%$ penyisihan surfaktan memiliki efek yang signifikan dengan nilai $\mathrm{P}<0,05$ (Tabel 4). Interaksi antar faktor diameter dan debit tidak memiliki efek yang signifikan pada \% penyisihan surfaktan dengan nilai $\mathrm{P}>0,05$ (Tabel 4).

Tabel 4. Analisis efek faktor diameter dan debit terhadap \% penyisihan surfaktan

\begin{tabular}{|c|c|c|c|c|c|}
\hline \multicolumn{6}{|c|}{ Estimateed Effects and Coefficience for \% Removal Surfaktan (coded units) } \\
\hline Term & Effect & Coef & SE Coef & $\mathrm{T}$ & $\mathrm{P}$ \\
\hline Constant & & 54,844 & 1,010 & 54,30 & 0,000 \\
\hline Diameter & $-14,574$ & $-7,287$ & 1,010 & $-7,22$ & 0,002 \\
\hline Debit & 17,959 & 8,979 & 1,010 & 8,89 & 0,001 \\
\hline Parameter^Debit & 2,593 & 1,296 & 1,010 & 1,28 & 0,269 \\
\hline
\end{tabular}
$\mathrm{S}=2,85661$
PRESS $=130,563$
$\mathrm{R}-\mathrm{Sq}=97,078$
$\mathrm{R}-\mathrm{Sq}$ (pred) $=88,30 \%$
$\mathrm{R}-\mathrm{Sq}(\operatorname{adj})=94,88 \%$

\begin{tabular}{|c|c|c|c|c|c|c|}
\hline \multicolumn{7}{|c|}{ Analysis of Variance for \% Removal Surfaktan (coded units) } \\
\hline Source & $\mathrm{DF}$ & Seq SS & Adj SS & Adj MS & $\mathrm{F}$ & $\mathrm{P}$ \\
\hline Main Effects & 2 & 1069,83 & 1069,83 & 534,917 & 65,55 & 0,001 \\
\hline Diameter & 1 & 424,82 & 424,82 & 424,817 & 52,06 & 0,002 \\
\hline Debit & 1 & 645,02 & 645,02 & 645,017 & 79,04 & 0,001 \\
\hline 2-Way Interactions & 1 & 13,45 & 13,45 & 13,445 & 1,65 & 0,269 \\
\hline Diameter^Debit & 1 & 13,45 & 13,45 & 13,445 & 1,65 & 0,269 \\
\hline Residual Error & 4 & 32,64 & 32,64 & 8,160 & & \\
\hline Pure Error & 4 & 32,64 & 32,64 & 8,160 & & \\
\hline Total & 7 & & & & & \\
\hline
\end{tabular}

Factorial plot terdapat main effects plot dan interaction plot. Main effects plot menunjukkan perbedaan rata-rata respon pada dua level faktor. Main effects plot menunjukkan pada variasi faktor diameter dan debit. Setiap titik mewakili rata-rata \% penyisihan surfaktan untuk satu level faktor. Garis tengah horizontal putus-putus berwarna biru menunjukkan rata-rata $\%$ penyisihan surfaktan untuk semua proses. Plot sebelah kiri menunjukkan bahwa media artifisial kapur-semen diameter $5 \mathrm{~mm}$ mampu menyisihkan surfaktan lebih baik dibanding diameter $10 \mathrm{~mm}$ (Gambar 9).
\% Penyisihan surfaktan pada media artifisial kapur-semen diameter 5 lebih rendah dibanding diameter $10 \mathrm{~mm}$. Plot sebelah kanan menunjukkan bahwa debit 240 $\mathrm{ml} /$ menit mampu menyisihkan surfaktan lebih baik dibanding debit $120 \mathrm{ml} /$ menit. \% Penyisihan surfaktan pada debit $240 \mathrm{ml} / \mathrm{menit}$ lebih rendah dibanding debit $120 \mathrm{ml} / \mathrm{menit}$. Interaksi antar faktor diameter dan debit tidak memiliki efek yang signifikan pada \% penyisihan surfaktan dengan nilai $\mathrm{P}>0,05$, sehingga tidak perlu dianalisis menggunakan interaction plot. 


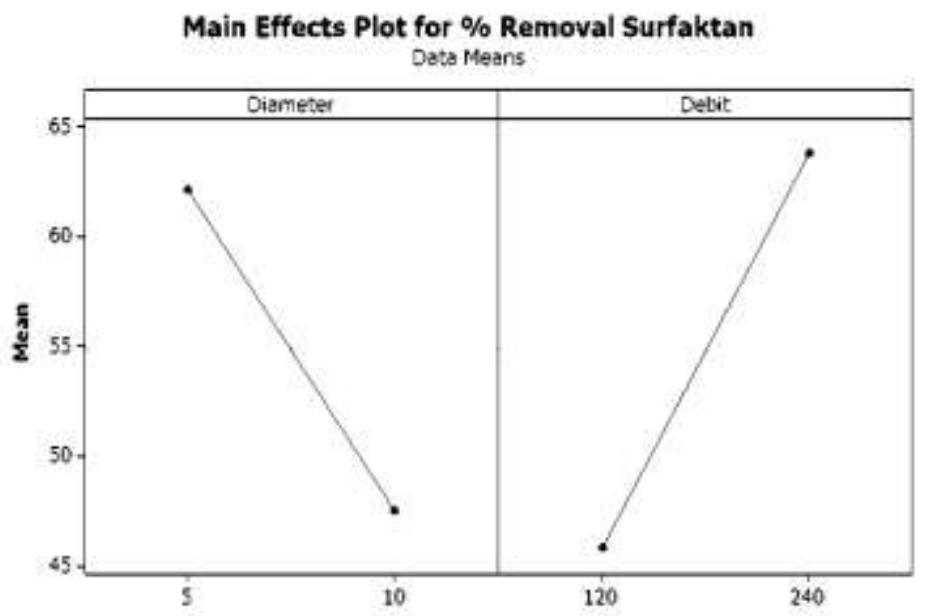

Gambar 9. Main effects plot \% penyisihan surfaktan

Diameter media artifisial kapur-semen dan debit dibandingkan dengan analisis menggunakan optimizer plot. Response optimizer digunakan untuk menghitung solusi optimal numerik untuk membantu mengetahui kombinasi faktor-faktor yang menghasilkan nilai respon yang optimal. Goal yang diatur pada response optimizer adalah maximize, yaitu $\%$ penyisihan surfaktan yang paling besar, untuk menentukan diameter dan debit yang mampu menyisihkan surfaktan paling baik. Goal yang telah ditentukan yaitu goal maximize dengan target $\%$ penyisihan surfaktan masing-masing adalah 70 dan 95 . Berdasarkan response optimizer, penyisihan konsentrasi surfaktan dapat optimal terjadi pada debit $240 \mathrm{ml} / \mathrm{menit}$ dan diameter media artifisial kapur-semen 5 mm (Gambar 10).

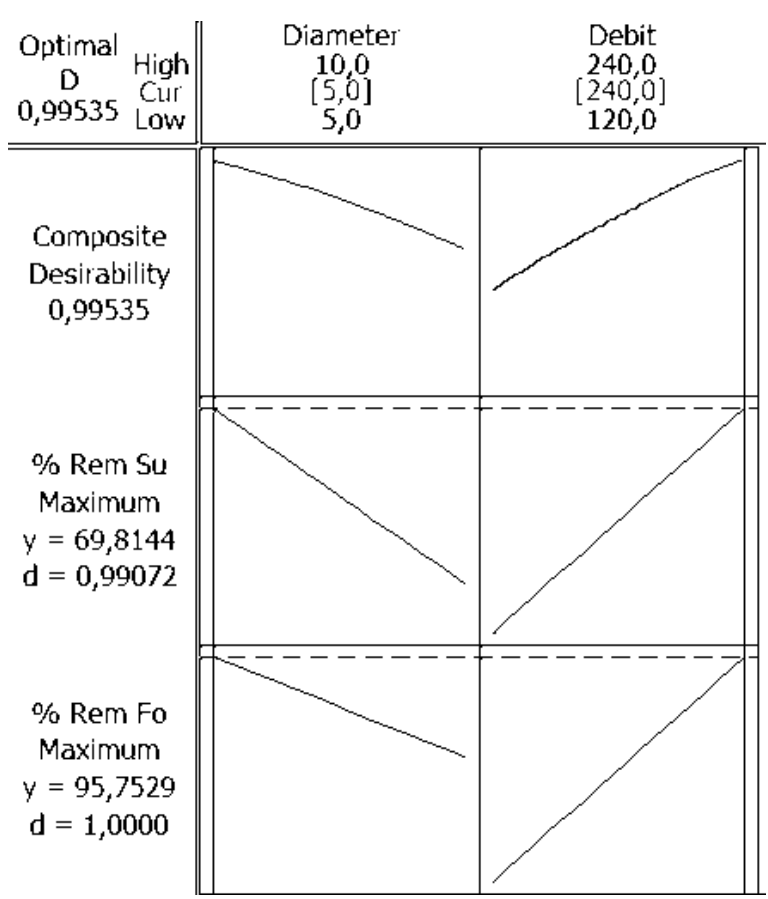

Gambar 10.9 Response Optimizer \% penyisihan surfaktan

\section{KESIMPULAN}

Media artifisial kapur-semen dengan diameter $5 \mathrm{~mm}$ dan debit $240 \mathrm{~mL} / \mathrm{menit}$ atau beban hidrolik $0,029 \quad \mathrm{~m}^{3} / \mathrm{m}^{2}$.menit menunjukkan penyisihan surfaktan pada air limbah laundry yang paling baik yaitu sebesar
$69,81 \%$. Faktor diameter dan debit memiliki efek yang signifikan dalam menyisihkan surfaktan. Interaksi antar faktor diameter dan debit tidak memiliki efek yang signifikan dalam menyisihkan surfaktan. 


\section{SARAN}

Hasil effluent dari media kapur-semen masih mengandung $\mathrm{pH}$ yang tinggi, sehingga diperlukan proses netralisasi agar kandungan $\mathrm{pH}$ memenuhi baku mutu. Diperlukan pengaplikasian reactor RF yang lebih besar agar waktu kontak dapat berajalan lebih lama sehingga penyisihan surfaktan menjadi lebih baik. Pengoperasian reaktor RF perlu dilakukan lebih lama untuk mengetahui titik kejenuhan dari media artifisial kapur-semen.

\section{REFERENSI}

[1] Sumisha, A., Arthanareeswaran, G., Thuyavan, Y. L., Ismail, A. F., Chakraborty, S., 2015, Treatment of laundry wastewater using polyethersulfone/polyvinylpyrollidone ultrafiltration membranes, Ecotoxicology and Environmental Safety, 1221, 174-179.

[2] Ciabatti, I., Cesaro, F., Faralli, L., Fatarella, E., Tognotti, 2009, Demonstration of a treatment system for purification and reuse of laundry wastewater, Desalination, 245, 451459.

[3] Mohan, S. M., 2014, Use of naturalized coagulants in removing laundry waste surfactant using various unit processes in lab-scale, Journal of Environmental Management, 136, 103-111.

[4] Kogawa, A. C., Cernic, B.G., Couto, L.G.D. do, Salgado, H.R.N., 2017, Synthetic detergents: 100 years of history, Saudi Pharmaceutical Journal, 25, 934-938.

[5] Kurniati, E., 2009, Penurunan Konsentrasi Detergent Pada Limbah Industri Laundry Dengan Metode Pengendapan Menggunakan $\mathrm{Ca}(\mathrm{OH})_{2}$, Jurnal Ilmiah Teknik Lingkungan, 1, 41-47.
[6] Srinet, S. S., A. Basak, Ghosh, P., Chatterjee, J., 2017, Separation of anionic surfactant in paste form from its aqueous solutions using foam fractionation, Journal of Environmental Chemical Engineering, 5, 1586-1598.

[7] Collivignarelli, M. C., Miino, M. C., Baldi, M., Manzi, S., Abb`a, A., Bertanza, G., 2019, Removal of nonionic and anionic surfactants from real laundry wastewater by means of a fullscale treatment system," Process Safety and Environmental Protection.

[8] Tchobanoglous, G., Stensel, H.D., Tsuchihashi, R., Burton, F., 2014, Wastewater Engineering: Treatment and Resource Recovery. 5th ed, Boston, McGraw-Hill Education.

[9] Cleary, S. A., 2005, Sustainable Drinking Water Treament for Small Communities Using Multistage Slow Sand Filtration, Waterloo, Master of Applied Science in Civil Engineering University of Waterloo.

[10] Notodarmodjo, S., Astuti, A., Juliah, A., 2004, Kajian Unit Pengolahan Menggunakan Media Berbutir dengan Parameter Kekeruhan, TSS, Senyawa Organik dan $\mathrm{pH}$, Proceeding ITB Sains \& Teknologi, 36 (A), 97-115.

[11] Bellier, N., Chazarenc, F., Comeau, Y., 2006, Phosphorus Removal from Wastewater by Mineral Apatite, Water Research, 40, 2965-2971.

[12] Wegelin, M., 1996, Surface Water Treatment by Roughing Filters A Design, Consttruction and Operational Manual. Duebendorf, Swiss Centtre for Development Cooperation in Technology and Management (SKAT).

[13] Suci, A. P. C. W., 2018, Reduksi Surfaktan Menggunakan Granular Kapur-Semen sebagai Sumber Ion $\mathrm{Ca}^{2+}$, Surabaya: Departemen Teknik Lingkungan ITS. 